\title{
PERÚ, 1850-1950. LA CONSTRUCCIÓN DEL PATRIMONIO RELIGIOSO
}

Fernando Armas Asín*

Durante el primer siglo de la República las élites políticas del país practican una fuerte política secularizadora, tanto en el campo económico como en el social, que afecta en forma progresiva a la Iglesia: reforma de las órdenes regulares en 1826, que implica la posesión estatal de muchos bienes eclesiales; redención de censos y otras imposiciones en 1829, 1864 y 1893, que condujo al término de este tipo de colocaciones de capitales. En general la abolición de diezmos $y$, como producto de la naciente expansión urbana de Lima y otras ciudades, la expropiación parcial o total de algunos inmuebles eclesiásticos. Este escenario tiene que ver con dos procesos paralelos que muestran profundas raíces en el tiempo: la dimensión internacional del conflicto entre mundo moderno y religión, y la dimensión nacional en torno a la ofensiva económica por reducir los espacios de intervención eclesiales y favorecer la economía moderna. Al fragor de estos desarrollos se plantea para la Iglesia la necesidad de defensa de sus fueros y derechos, particularmente de sus bienes. Esta es la base de su interés tanto por lo jurídico como por el discurso claramente apologético del carácter privado de su patrimonio; así como por defender y utilizar adecuadamente su patrimonio cultural. De este creciente interés trata precisamente el presente artículo.

\section{SECULARIZACIÓN Y DEFENSA DE LA IGLESIA}

En las primeras décadas republicanas no hay un interés real por la defensa discursiva de los bienes de la Iglesia, ni entre los eclesiásticos políticos como Mariano José de Arce o Francisco Javier de Luna Pizarro, ni entre los apologistas como Mateo Aguilar o José Ignacio Moreno, que se orientaron más bien al desarrollo de temas sobre la soberanía, autoridad o supremacía del Papa, amén de las formas de organización política del Perú'. Recién será a mediados del siglo $\mathrm{XIX}$ cuando esto cambie.

Así, en medio del progresivo esfuerzo secularizador en materia económica por parte del Estado, es interesante apreciar la manera en que la defensa de los bienes de la Iglesia como propiedad privada e inalienable, conciliando los avances del derecho moderno con el derecho clási$\mathrm{CO}$, se convierte desde 1855 en un argumento central. En el marco de la Convención Nacional de ese año, cuando el grueso de los diputados estuvo a favor de la eliminación del diezmo y se consultó a los cabildos eclesiásticos de la república, el Cabildo Eclesiástico de Lima -Lucas Pellicier, Bartolomé Herrera, Pedro José Tordoya, etc.- la rechazó en términos absolutos pues, para ellos, su existencia derivaba de un "derecho

- Instituto de investigaciones, Facultad de Ciencias de la Comunicación, Turismo y Psicología, Universidad de San Martín de Porres, Lima.

1 Inciuso durante la reforma de las órdenes regulares de 1826, la resistencia más consistente desde el punto de vista jurídico fue el alegato impreso por José Ignacio Moreno, donde reconociendo la posibilidad de una reforma de esa naturaleza cuestionaba los procedimientos pues, para este sacerdote diocesano, se debió pedir la anuencia del Papa, lo cual nos ubica en el viejo problena de la jurisprudencia patronal tvéase losé lgnacio Moreno. Abuso del poder contra la libertad de la Iglesia. Lima, Imp. González, 1831). Cuando en 1829 se pretendió que el diezmo fuera aplicado no sobre la producción comercial agraria, sino sobre la utilidad bruta de esta, el Cabildo Eclesiástico de Lima reacciono, negando al poder civil legitimidad para reformar la legislación eclesiástica, no solo amparándose en el carácter divino del diezmo, sino en que al set parte del derecho eclesiástico le competia su modificación únicamente a Roma, volviendo a los argumentos de J.I. Moreno (Cabildo Eclesístico de Lima, Representación del Deán y Cabildo de esta Sta. iglesia Metropolitana al Congreso Constituyente. Lima, Imp. Masías, 1829). 
de propiedad" de la Iglesia. Fundamentaban esa propiedad en una legitimidad histórico-teológica -ley divina y natural- para percibir la renta decimal. De allí se desprendía que la autoridad civil no podía legislar sobre dichas materias y, si se deseaba modificarla, había que solicitarlo a Roma.

Esta idea de propiedad absoluta y de libre disponibilidad permitió a la Iglesia defender el conjunto de sus bienes, regular o secular, y la idea de poder adquirir o vender libremente ${ }^{2}$. En esta última línea, Bartolomé Herrera escribiría aparte un texto, donde asumiendo la legislación existente sobre las órdenes regulares y buscando conciliarla con la forma tradicional de desenvolvimiento de dichas instituciones, las defiende de la excesiva intromisión estatal exaltando el derecho a tener bienes de su propiedad y a practicar la compra-venta de los mismos, algo a todas luces no deseado por las mentes más regalistas de su tiempo. Aunque la Carta Constituyente de la Convención no entró en vigencia, el Congreso Constituyente de 1860 sí recogió la eliminación del diezmo, primicias y derechos parroquiales, pero esta no se produjo en la práctica, a pesar de que Herrera realizó una defensa de las vinculaciones eclesiásticas que para él representaban grandes ventajas para el país, por cuanto permitían la manutención del clero y la permanencia de un "patrimonio" intangible, es decir bienes que pasaban de generación en generación. Presentó incluso un proyecto constitucional alternativo que fue desechado ${ }^{3}$.

Ante la arremetida liberal Herrera fundará el periódico $E /$ Católico para defender los intereses de la Iglesia, sus derechos tradicionales y la propiedad de sus bienes. Lo acompañarán Agustín Guillermo Charún, Pedro Tordoya, José Sebastián de Goyeneche $y$ otros obispos, rechazando los argumentos liberales y amparándose en los viejos escritos de Moreno sobre el carácter divino de la institución y sus derechos sociales adquiridos. No hay que olvidar además a los discípulos de Herrera: el futuro obispo de Trujillo (1859) y arzobispo de Lima (1873) Francisco Orueta y Castrillón, y Manuel Teodoro del Valle, obispo de Huánuco (1865). Ambos defendieron en el Congreso liberal de 1867 los derechos tradicionales de la Iglesia contra el proyecto de desamortización de sus bienes presentado por Fernando $\mathrm{Ca}$ sós. Como lo habían hecho frente a la ley de 1864 sobre redención de censos y capellanías y como lo harían posteriormente (1868) frente a la abolición de algunos derechos parroquiales. En todas estas defensas hicieron énfasis en los derechos de propiedad de la Iglesia y en los principios generales del derecho público y moderno ${ }^{4}$. Del Valle, particularmente, ayudó además a Manuel Tovar en la fundación del periódico La Sociedad, primero, y luego en 1867 animó la fundación de la Sociedad Peruano-Católica para oponerse a la arremetida liberal y defender a la Iglesia con análogos argumentos.

Igualmente otro discípulo de Herrera, Ezequiel Moreyra, obispo de Ayacucho (1866), escribió su parecer en 1867 sobre el proyecto de eliminar las primicias y derechos parroquiales 5 . Interesante esta generación de eclesiásticos, herederos de Herrera, pues prolongan una lucha discursiva de apología de los intereses económicos y sociales eclesiales. Como luego de la guerra del Pacífico lo harán los obispos Manuel Bandini o Juan Ambrosio Huerta frente a la secularización social.

Por último habría que señalar al franciscano Pedro Gual y Pujadas (1813-1890), quien se destacó igualmente por sus obras en defensa de los diversos derechos de la Iglesia, entre ellos el de la propiedad. Trató el tema por vez primera en el tomo segundo de El equilibrio entre las dos

2 Cabildo Eclesiástico de Lima. Exposición del Cabildo Metropolitano de Lima a la Convención Nacional sobre la exclusión de falsos cultos y sobre los derechos de liberlad y de propiedad de la Iglesia, pp. 1-3.

3 Banolomé Herrera. fl clero regular y sus bienes ante la lei polthica y civil. Arequipa, Imprenta de Francisco y Hermanos, 1855.

4 Francisco Orueta y Castrillón. Exposición que el timo. St. Obispo de Iruillo ha ditijido al Supremo Cobierno sobre la ley de redención de censos y cofradias. Truijillo, La Ilustración, 1865; Id. Exposición... sobre el proyecto de lei de desamortización de bienes eclesiásticos. Trujillo, F.W. Rázuri, I867; k. Informe... sobre el proyecto de lei de reducción de derechos de matrimonios y abolición de las cuartas funerales que por los canones deben satisfacerse a los llmos. Sres, Obispos. Trujillo, F.W. Razuri. 1868; Manuel Teodoro del Valle, informe que el llmo. Sr. . Obispo de lluśnuco dirije sobre el proyecto de lei evinguiendo los patronas y capellanias laycales de libre nominación y adjudicándolas a los establecimientos de instrucción. Lima, I.M. Masias, 1868; Id. Exposición sobre la desamortización de los bienes eclesiásticos dirigida al Soberano Congreso. Lima, José M. Noriega, 1867; Id. Informe sobre el proyecto rebajando los derechos parroquiales y extinguiendo las cuartas funerales. Lima,
J.M. Maslas, 1868 .

5 José F. E. Moreyra. informe... rejativo al proyecto de ley de supresión de primicias y derechos parroquiales. Ayacucho, s.i., 1867. 
potestades $y$ posteriormente, en forma extensa, en $\mathrm{El}$ derecho de propiedad ${ }^{6}$. Afirmó el derecho de la Iglesia a poseer bienes e ingresos económicos, basándose en la tradición histórica y en las fuentes biblicas, así como en los ejemplos modernos de cualquier institución con exigencias de personal y gastos. En ese sentido redactó múltiples ejemplos comparativos entre la iglesia $y$ cualquier otra instancia respecto a tener necesidades, pagar por el justo trabajo, etc. Recordemos que el segundo texto fue publicado en 1872, al inicio del gobierno liberal de Manuel Pardo, en un contexto de escritos de los regalistas Francisco de Paula González Vigil y Francisco Javier Mariátegui, clamando por una nacionalización de los bienes de religiosos?

\section{LA LEGISLACIÓN PATRIMONIAL Y EL CUIDADO DE LOS BIENES}

El interés de la Iglesia por una legislación patrimonial que incidiera específicamente en el cuidado de sus propios bienes no tiene una antigüedad de años, como algunos pudieran presumir. Si bien la Iglesia, al igual que otras instituciones antiguas y medievales, definió aspectos como la delimitación, usufructo y destino de sus bienes, no fue sino tras los convulsionados siglos XVIII y XIX que esto se hizo más evidente en otros aspectos apenas tocados previamente. Había motivos de sobra para ello: tanto la arremetida legislativa liberal como las guerras y expoliaciones hacían necesario contemplar variados aspectos para el adecuado cuidado y control de los bienes que les quedaban.

Así para el siglo XIX notamos un interés creciente en el tema desde el pontificado y la curia romana, que se grafica muy bien en el decreto de la Sagrada Congregación de Indulgencias, en 1897, sobre creación de uniones o asociaciones piadosas, donde se insiste en las formas de adquisición de bienes y sus pertenencias; o en el decreto de 1859 de la Sagrada Congregación de los Ritos sobre el cuidado debido a las reliquias insignes; 0 , yéndonos a un nivel local, en el decreto del Arzobispado de Lima sobre los inventarios en las parroquias o iglesias de la arquidiócesis, dado en 1900 durante una visita episcopal. Se precisa allí la necesidad de velar en las fábricas de las parroquias por el tesoro de los templos, exigiendo la elaboración de un inventario en libros del mobiliario, vasos sagrados y otras alhajas, ornamentos sagrados y ropa blanca, libros y margesí de los bienes, con descripción breve de su estado. Tal exigencia alcanzaba también a las hermandades y asociaciones para que dieran cuenta de lo que tenían y se establecía asimismo que los párrocos no podían hacer contrato alguno sin la autorización episcopal, enviándose copia del inventario al Arzobispado 8 .

Al calor de los acontecimientos, la Iglesia iría pues delimitando su legislación de bienes, luchando no solamente contra el Estado y el liberalismo secularizador, sino también contra alcaldes, mayordomos y despenseros que en las parroquias o en el campo empezaron a tener fricciones con los párrocos o con la Iglesia jerárquica al tomar control directo de los bienes que administraban?. La Iglesia, como personalidad jurídica y con idénticas prerrogativas que otras instituciones en la sociedad peruana, poco a poco fue pues normativizando su derecho de bienes sustentado en teoría -sea bienes de regulares, sea diocesana- en un ambiente de economía moderna. Pero la existencia del patronato y las interferencias estatales para su compra y venta y pleno dominio -en la esfera regular- hacían de ella una quimera.

Curiosamente a fines del siglo $\mathrm{XIX}$ e inicios del XX, los liberales secularizadores, en tanto regalistas,

6 Pedro Gual. El equilibrio entre las dos potestades, o sea, los derechos de la Iglesia vindicados contra los ataques del Dr. D.F. de P.C. Vigil en su obra titulada "Delensa de la autoridad de los gobiernos y de los obispos contra las pretensiones de la curia romana". Barcelona, Imp. Pons y Cia., I852, volumen II; Id. EI derecho de propiedad en relación con el individuo, la sociedad, la lglesia y las corporaciones religiosas, obrita escrita por ..., contra los sistemas del comunismo moderno y un opúsculo recientemente publicado por el Dr. Francisco de P. C. Vigil. Lima, La Sociedad, 1872.

7 Para profundizar la teología y los aportes intelectuales de Pedro Gual remitimos a la tesis de Marcelino Cuesta Alonso, La teología apologética de Pedro Gual y Pujadas. Pamplona, Universidad de Navarra, 1999 (tesis doctoral en Teologia. Pro-Manuscripto).

8 Carlos García Irigoyen. Legislación eclesiástica del Arzobispado de Lima, tomo I (1898-1901). Lima, Imp. y Lib. San Pablo, 1902. Decreto sobre la creación y agregación de uniones piadosas y otras sociedades de la misma indole. CSC de Indulgencias del 15 de agosto de 1897; CSC de los Ritos, Decreto sobre reliquias insignes del 27 de junio de 1859; Decreto del Arzobispado sobre inventario en las parroquias o iglesias de la arquidiócesis. Huacho, 2 de mayo de 1900 . También hay un decreto pontificio donde no se permite luz eléctrica en los altares, pp. 5-7, 104 y $248, I$ y 100, II.

9 Véase al respecto la "Visita pastoral de don Pedro Pablo Drinot y Piérola, obispo de Huánuco". Edicto de Bienes Eclesiásticos de Mons. Drinot y Piérola, Jauja 10-1X-1900. 
habían provocado que la modernidad no se terminara de establecer en este punto. En 1896 Germán Leguía y Martínez presentó en el Congreso un proyecto para derogar los artículos de los códigos civiles y de enjuiciamiento y los decretos de noviembre de 1862 y febrero de 1863 , que sometían los bienes eclesiásticos de comunidades religiosas a engorrosos trámites para su libre disposición, lo cual era en el fondo una forma moderna de vinculación. Así, en adelante, las entidades religiosas tendrían pleno dominio de sus bienes como particulares que eran. Mariano $\mathrm{H}$. Cornejo combatió dicho proyecto bajo el argumento de que esos eran bienes del Estado. La ley empero fue aprobada y promulgada el 30 de setiembre de 1901. Más adelante, el 25 de octubre de 1901, se autorizó además a las comunidades religiosas a hipotecar sus bienes sin ninguna restricción.

Un lugar importante en la legislación universal eclesial le compete sin duda al Código de Derecho Canónico de 1917, que contuvo normas específicas sobre el cuidado de bienes. Adaptándolo a la realidad local, y en medio de la dación del Código Civil de 1936, hay que destacar el Acuerdo de la Asamblea Episcopal sobre Bienes Eclesiásticos del año 1938.

La Asamblea definió que los bienes eclesiásticos podían ser de tres tipos: los que tenían títulos perfectos y por tanto no se podían vender, los que la Iglesia poseía efectivamente pero cuyos títulos definitivos no estaban inscritos en los registros de propiedad y los bienes usurpados, para cuya recuperación había que ejercer presión. A continuación delimitó la noción de bien, separándolo de las rentas de clérigos y fundaciones laicas (filantrópicas). Dijo -basándose en el Código de Derecho Canónico (c. 1496)- que la Iglesia podía adquirir bienes por ocupación, prescripción, donación, acceso, etc., sin pedir permiso a nadie. El Papa tenía jurisdicción, pero no propiedad, sobre todos los bienes. Ni la feligresía ni los pobres tenían personería jurídica (sujeto de propiedad) sobre aquellos, salvo la feligresía de las parroquias o las cofradías canónicamente constituidas. La Iglesia o la sede apostólica eran sujeto de dominio, no feneciendo este; si se extinguía una persona moral eclesiástica, pasaba a la persona inmediata superior, salvo especificación en contrario (c. 1499.2/1501). El documento en suma cuidaba de que la legislación civil no fuera contraria "al derecho divino" y se cumpliera en materia de contratantes (c. 1529).

También de acuerdo con el Código de Derecho Canónigo se establecían los requisitos de venta -justiprecio, causa justa, licencia del superior(c. 1530,1 y 2), ratificando que los conventos, monasterios, beaterios, etc. tenían libertad al respecto, por la ley del 30 de setiembre de 1901 ya revisada. Dichos requisitos alcanzaron igualmente a los bienes de parroquias (Resolución Suprema del 4 de octubre de 1902, comprendida en la misma ley) y seminarios (Resolución Suprema del 17 de octubre de 1911).

Pero a continuación, y en relación con el Código Civil de 1936, que no especificaba el estatus jurídico de la Iglesia, se pretendía que los bienes eclesiásticos debían continuar rigiéndose por el derecho general y el específico eclesiástico dados por el poder civil, y que no fueron derogados. Parece que este documento se redactó porque el código de 1936 dispuso que las asociaciones $y$ demás personas jurídicas tenían 3 meses para regular su situación, inscribiendo en el registro correspondiente sus escrituras y estatutos, ante lo cual se alegó que no se había legislado específicamente para ellos.

Las corporaciones de derecho eclesiástico gozaban de personería jurídica y se aceptaban como personas jurídicas de derecho privado, según el Código Civil. Aunque frente al hecho de que siendo un código de las personas "jurídicas de carácter civil (art. 41) inscritas de Registro", a los obispos les hubiera gustado que el Estado, al reconocer a la Iglesia como sociedad autónoma, les hubiera otorgado propiedad jurídica especial. En verdad, como sabemos, las corporaciones eclesiásticas son personas jurídicas de carácter civil, y ese fue el espíritu del código de 1936.

Volviendo a la naturaleza de los bienes que poseía la Iglesia que -como ya hemos visto- eran de tres tipos, ¿qué bienes se podía vender? Los que tuvieran títulos perfectos. Los otros había que regularlos, sanearlos jurídicamente, para 
luego venderlos si convenía. Los bienes en disputa y sin títulos, por otro lado, debían ser objeto de arreglos equitativos y ser vendidos, según mandaba el derecho canónico (c. 1530). Bienes como ganados y otros había que venderlos, aunque "la tendencia de los pueblos es hacerlo(s) desaparecer". Las imágenes con profesión de exvoto no debían venderse sin autorización de la Santa Sede -aunque el donante estuviera de acuerdo-, según decreto de la Sagrada Congregación del Concilio del 14 de enero de 1922. Cualquier exvoto en general se debería igualmente vender con autorización de la Santa Sede según la misma Sagrada Congregación del Concilio, en su decreto del 12 de julio de $1919^{10}$.

Por último el documento recordaba que el 28 de junio de 1938 el gobierno había señalado que al abolirse los diezmos se abolieron los expolios, que eran intervenciones estatales a los testamentos de obispos, aplicando los bienes a objetos definidos, pudiendo desde entonces ser parte de los patrimonios episcopales.

\section{LA LUCHA POR LOS BIENES}

Al lado de esta preocupación creciente por una legislación patrimonial, en perspectiva de defensa, aparece también paulatinamente una conciencia por la protección práctica de los bienes. No es fácil ello, empero, pues prima todavía un desconocimiento mayúsculo de su valor económico y cultural. El noble francés Paul Marcoy (1810-1880), en viaje por el Perú, recordaba que estando en el Cuzco decimonónico le expresó a un amigo su preferencia por un hermoso cuadro existente en el convento de la Recoleta. Al poco tiempo su amigo se lo obsequió, pues se solía hacer este tipo de regalos, incluso con la activa participación de gente de la misma iglesia:
"Un monje de la Recoleta a quién le había ofrecido, a través de una vieja beata acostumbrada a este tipo de cosas, una onza de oro... no había vacilado en cargar su conciencia con este robo sacrílego" "11. La conocida anécdota muestra a un Marcoy católico y con un respeto especial por los bienes patrimoniales, debido sin duda a su experiencia europea y al influjo de una época en que empezaban a tomar forma estas ideas. Pero también es un suceso atípico en el país, pues son bien conocidos los casos de muchísimos otros viajeros, protestantes y católicos, grandes coleccionistas o comerciantes de obras de arte para museos, institutos o familias europeas o norteamericanas, que no tuvieron reparos en hacerse de apreciables cantidades de bienes prehispáni$\cos$ y coloniales a su paso por el Perú.

Para inicios del siglo $X X$ se incrementan los problemas que debe afrontar la Iglesia en esa línea. En 1913, en Huancayo, los comuneros de Pilcomayo denuncian a su párroco ante el Arzobispado de Lima, acusándolo de intentar despojarlos de los bienes de la comunidad destinados para el culto, que según ellos siempre habían estado en manos de los comuneros ${ }^{12}$. Es una evidencia de la confrontación rural entre cofradías y hermandades por los bienes parroquiales. En Lima, en 1915, el monasterio del Prado litiga contra Santos Castagnola, enfiteuta que desea consolidar el dominio sobre una fracción de un bien inmueble que posee. La defensa religiosa es principista $^{13}$. Por su parte el monasterio de Jesús y María, entre 1916 y 1918 , se ve obligado a litigar contra la Municipalidad de Lima, que le ha embargado los alquileres que pagan Enrique del Solar Mendiburu y Lizandro Campos, por negarse a cancelar una deuda por obras de pavimentación delante de su edificio, y que cada vecino debe costear. El litigio fue desde primera instancia hasta la Corte Suprema ${ }^{14}$.

10 Episcopado Peruano. Acuerdos de la Asamblea Episcopal sobre Bienes Eclesiásticos. Lima, Talleres Gráficos Lumen, 1938 , pp. 6-7 y 9.

11 Paul Marcoy, Viaje a través de América del Sur. Del oceáno Pacifico al océano Atlántico. Lima, Instituto Francés de Estudios Andinos-Pontificia Universidad Católica del Perú-Banco Central de Resenva-Centro Amazónico de Antropología Aplicada, 2001 (1872-1873), tomo I, Cuzco.

12 AAL (Archivo Arzobispal de Lima). CMN (Comunicaciones). XL. 249. Huancayo 1913.

13 Federico Philips. La consolidación de enfiteusis no puede verificarse en una sola parte del fundo enfitéutico. Defensa oral del Monasterio del Prado hecha por el aboga do... ante la Exma. Corte Superior de Justicia, en juicio contra el indicado monasterio, sigue su enfiteutista D. Santos Castagnola, intentando consolidar el dominio, en una fracción de enfiteusis que posee. Lima, 1915.

14 Id. Interdicto del Monasterio de jesús Maria contra la Municipalidad de Lima por despojo de arrendamientos. Defensa del Monasterio hecha ante la Corte Suprema. Lima C.F. Southwell, 1918.

15 AAL. CMN. XLII. 112. Arequipa 1922. Remite la copia de la reconsideración solicitada por el Ministerio de Culto a la resolución suprema del 4 de noviembre. 
En 1922, el presidente Leguía ordenó que los cementerios de la república pasaran a depender de los municipios, causando serios reparos del clero, en una tendencia secularizadora ya vista desde el siglo anterior ${ }^{15}$.

Ante estas complicaciones, el cuidado por los bienes vuelve a preocupar al Arzobispado de Lima, que en 1920 dispone por decreto que todos los párrocos y vicepárrocos envíen a la secretaría arzobispal un margesi de sus propiedades inmuebles $^{16}$. Interesa no solo conocer su cantidad y su valor, sino sobre todo su situación jurídica, para saber si efectivamente la Iglesia ejerce posesión sobre ellos o están siendo usurpados por terceras personas. En 1922 el párroco de San Pablo remite el estado de los procesos judiciales de la Iglesia pendientes en su parroquia, con una defensa cerrada de los bienes ${ }^{17}$. Los casos se multiplican y hay censos que no se cobran, enfiteutas que no se reconocen como tales o simplemente usurpadores de inmuebles abandonados por la Iglesia. En 1925 hay una disposición para que todos los capellanes de capellanías colativas entreguen a la sindicatura eclesiástica la administración de los bienes que constituyen su capellanía ${ }^{18}$. El proceso de desaparición de censos, por redenciones o sustracción a la legalidad, se acentúa.

Mientras tanto en el campo aumentan también los problemas por usurpación lisa de bienes. Por ejemplo en la parroquia de Huancayo, de la diócesis de Huánuco, donde el cura del lugar no solo enajena los bienes de cofradías de los fieles, sino que procede a venderlos, provocando un largo litigio, con investigación eclesiástica de por medio e intervención del Arzobispado de Lima, en una confrontación que permite constatar hasta dónde puede llegar la expoliación de bienes por un miembro del mismo clero ${ }^{19}$. EI XIV Sínodo Arquidiocesano de Lima, en enero de 1935, aprobó una serie de normas sobre administración de bienes, en el espíritu del Código de Derecho Canónico y de las normas de los sacros colegios pontifi$\operatorname{cios}^{20}$. En esa misma línea debemos recordar la preocupación de la Carta de la Asamblea Episcopal de $1938^{21}$.

Con los años esta diversidad de litigios, cuyo núcleo central es la lenta preocupación por la defensa patrimonial, va a confluir en una fricción con el Estado. En 1941, un pedido desde el Congreso del senador Ruiz Bravo -solicitando un informe detallado sobre la administración de los bienes de las iglesias, monasterios, conventos, parroquias y santuarios- hecho al Ministerio de Justicia y Culto y trasladado por este a los obispos, ocasiona que por oficio del 27 de octubre de 1941 al ministro, el obispo de Huánuco rechace dicho pedido "pues renunciarían (el clero) a su derecho, permitiendo intromisiones en la dirección eclesiástica", en una clara reacción a la injerencia patronal.

Hay independencia de jurisdicciones -continúa el oficio- pues la Iglesia es una sociedad independiente $y$ esta personalidad jurídica es reconocida por el Estado. La Iglesia tiene además, desde su origen, derecho a adquirir y poseer bienes, lo que se argumenta históricamente aduciendo que Cristo tuvo su caja común (loculus), continuada luego en el imperio romano por la comunidad cristiana. Por otro lado las Leyes de Indias (1. 5. Nueva Recopilación) le reconocen el derecho y propiedad de bienes. Las leyes de la república igual, y el Concilio Plenario Latinoamericano en su c. 288 expresa: "el auto dominio de los bienes... reside en el Romano Pontífice $y$ el dominio directo y útil pertenece a la Iglesia o instituciones eclesiásticas" 22 .

La reacción no es desmesurada, pues ya durante el gobierno de Óscar R. Benavides (19331939), y más durante el primer gobierno de Manuel Prado Ugarteche (1939-1945), hay diversos

\footnotetext{
16 AAL. CMN. XLI. 480. 1920.

17 AAL. CMN. XLII. 69. San Pablo 1922.

18 AAL. CMN. XLII. 321. Lima 1925.

19 AAL. CMN XLII. 81, 85, 106 y 120. Huánuco 1922 y 1923.

20 Sinodo de Lima. Actas y Constituciones del XIV Sinodo de la Arquidiocesis de Lima. Lima, 1935.

21 Episcopado Peruano. Acuerdos de la Asamblea Episcopal sobre Bienes fclesiásticos, pp. 1-9.

22 AAL. CMN. XIVII. 54. Huánuco 1941. La contestación terminó siendo del episcopado en su conjunto. AAL. CMN. XIVII. 67. Arequipa 1941, donde puede leerse que el obispo arequipeño Mariano Holguín, en carra del 3 de diciembre de 1941, acepta que incluyan su nombre en el memorando que prepara el obispo para contestar al ministro.
} 
roces con un Estado que empieza a poner en práctica su vieja preocupación por una política de conservación de los bienes culturales, partiendo de la premisa de que esta constituye un deber estatal pues todos los bienes, más allá de sus pertenencias privadas o no, son bienes nacionales $^{23}$. Por Ley № 8853 del 9 de marzo de 1939, al final del gobierno de Benavides se crea el Consejo Nacional de Conservación y Restauración, integrado por once miembros nombrados por el Poder Ejecutivo, encargado de velar por los lugares históricos, monumentos, edificios y objetos artísticos de origen colonial que tengan un sentido histórico.

El referido consejo debía hacer un inventario y catálogo nacional de dichos elementos declarándolos intangibles, y efectuar su registro oficial. Debía además impedir su salida del país, así como establecer una política de restauraciones de edificios y objetos artísticos, dictaminar la pertinencia de tal o cual restauración antes de que los municipios autorizaran las obras y opinar sobre la conveniencia de declarar monumento nacional algún lugar o edificio en particular ${ }^{24}$. Igualmente debía organizar exposiciones por interés nacional de objetos o lugares artísticos, cuyos dueños -si los tenían-, debían correr con los gastos $y$, adicionalmente, organizar exposiciones individuales de los mismos objetos cada año.

Aunque luego fue reglamentada, era una ley bastante vertical en el control de los bienes de los propietarios privados, pues aunque se les reconocía su condición de tales, estaban sujetos al Estado en materia de administración. Sin duda su misma naturaleza inédita hasta entonces causó mucho temor, particularmente en la Iglesia. A su interior, ya el 6 de mayo de 1939 se había nombrado una comisión consultiva en asuntos de enajenación de bienes de religiosos, integrada por eminentes católicos laicos y eclesiásticos, que fue reorganizada por el Arzobispado el 13 de enero de $1944^{25}$. A todas luces la actuación del Consejo Nacional implicó roces con ella. Y los hubo, pues este empezó rápidamente su tarea de inventariar los bienes culturales de origen colonial, pidiendo a la Iglesia autorización para ingresar a templos, conventos y monasterios de Lima y el resto de la república a efectuar dicha labor.

La resistencia del clero fue intensa. Atemorizada por las implicancias que tales incursiones pudieran tener -ser un camino al despojo de sus escasos bienes, dar indicios a ladrones y traficantes de los objetos específicos que poseía-, la Iglesia reaccionaba como cualquier institución que venía de la mala experiencia del siglo XIX y que veía en esta actitud conservacionista nuevos motivos de injerencia estatal. Ese es el verdadero tenor del oficio del Episcopado del 18 de diciembre de 1943 al Ministerio de Relaciones Exteriores y Culto, donde la Iglesia se excluye del trabajo de inventario que hace el Consejo Nacional y argumenta que ella "administra y dispone de un tesoro artístico", y que tiene los medios para conservarlo26.

iCelosa conservacionista! El 28 de abril de 1944, el ministro de Relaciones Exteriores y Culto traslada al arzobispo de Lima un oficio enviado por el ministro de Educación Pública, dando cuenta de la denuncia presentada por el

23 La preocupación republicana, desde el punto de vista legislativo, tiene larga data. En 1822 un decreto prohibió extraer objetos de huacas y comercializarlas fuera del pais, lo que no impidió la destrucción de estas y la exportación de piezas en grandes cantidades. Un decreto de 1893 ratificó la prohibición anterior, en el marco de una coyuntura de interés sobre el pasado nacional. Tampoco resultó efectiva y las expoliaciones continuaron. El Instituto Histórico del Perú formula en 1907 un proyecto de ley que declara patrimonio nacional todos los sitios arqueológicos, los cuales si están en manos privadas pueden ser expropiados por el Estado, para protegerlos, e impide igualmente la exportación de piezas, reglamentando su estudio y promoviendo su conservación. Estas ideas se presentaron en el Congreso Científico Panamericano de Buenos Aires en 1910 . Fruto de esta nueva sensibilización, el Decreto Supremo $\mathrm{N}^{\circ} 2612$ del 19 de agosto de 1911 prohíbe toda exploración y excavación sin permiso oficial y autoriza únicamente la exportación de réplicas de las piezas más relevantes. Curiosamente, poco después, se da el reseñado caso de la exponación de piezas de la expedición Yale-National Geographic, al final del primer gobiemo de Leguía. En el segundo régimen de este, y dentro de la lógica populista de sus primeros años, se emite el decreto supremo de 10 de junio de 1921 que declara a los monumentos y objetos de los antiguos pobladores del Perú como de la nación y prohibe su extracción y exportación, reiterando la ley de 1911 en el sentido de autorizar, con permisos especiales, la exploración, extracción y exponación de réplicas. La resolución del 5 de julio de 1921 , del Congreso Regional del Sur, encargó a la universidad cuzqueña el cuidado y protección de los sitios prehispánicos y coloniales de su departamento. A fines de ese régimen (1929) se da la Ley $\mathrm{N}^{\circ} 6634$, que repile conceptos anteriores y ordena establecer un registro obligatorio de todos los poseedores de bienes, para evitar expoliaciones o- legalizar las posesiones existentes.

24 En estos años empieza la vorágine por nombrar monumentos historicos a diversos edificios o lugares históricos. Por ley 8054 del 14 de marzo de 1935 se declaró monumento nacional la capilla de La Merced de Huancayo y se ordenó su restauración con fondos públicos. Por ley 9342 del 18 de febrero de 1941 se declaró monumento nacional la iglesia de Santiago Apóstol de Lampa y se declaró zona turistica la ruta de Lampa a Ayaviri. Por ley 9395 del 30 de setiembre de 1941 se declaró igualmente monumento nacional la iglesia de Tauca, en Pallasca. Por ley 10018 del 13 de noviembre de 1944 se hizo lo mismo con la iglesia de San Pedro de Corongo. Y por ley 10019 de ese mismo día se convirtió en monumento histórico colonial el templo de Checacupe, en Canchis, Cuzco.

25 AAL. CMN. XLVIII. 3A. Lima 1941.

26 AAL. NSC (Notas del Superior Cobierno). XV. 713. Lima 1944. Oficio de recibo del Ministerio de Relaciones Exteriores y Culto (5olf y Muro) del 10 de febrero de 1944, del oficio del Arzobispado sobre el Consejo Nacional; "dicho oficio ha sido transcripto al Ministerio de Educación Pública". 
Consejo Nacional de Conservación y Restauración de Monumentos Artísticos e Históricos en el sentido de que en la iglesia de La Soledad de Lima se ha "sustraído" un cuadro ya inventariado, habiéndosele entregado a un restaurador. Similar hecho ha ocurrido con un grupo de cuadros en el monasterio de la Concepción. En ambos casos -se señala- estos traslados y restauraciones se han hecho sin autorización del Consejo Nacional ${ }^{27}$. Se queja asimismo el Consejo por el oficio del Episcopado del 18 de diciembre de 1943, aduciendo que el concepto eclesial de propiedad privada es errado pues la propiedad es "del país entero que ha acumulado aquella riqueza en el transcurso de los siglos". Por eso argumentan que la ley 8853 , "sin desconocer el derecho de propiedad de la Iglesia y sin renunciar al deber del Estado a cautelar el patrimonio artístico e histórico de la Nación", obliga al Consejo Nacional a levantar un inventario, impedir la salida de esos tesoros del país, disponer las conservaciones necesarias para que no sufran alteraciones y programar exhibiciones periódicas que sean necesarias "para que la ciudadanía conozca cuál es la preciosa herencia de la cultura peruana". Para el Consejo Nacional el oficio del Episcopado busca salirse del marco de la mencionada ley y termina afirmando que hay que preservar los objetos artísticos de la "ruinosa administración" de que han sido objeto, particularmente a manos de la Iglesia.

Es obvio el enfrentamiento de pareceres: de una parte una institución con experiencia de confiscaciones $y$ expoliaciones de bienes, $y$ de la otra un organismo estatal, dependiente del Ministerio de Educación, que plantea la idea de propiedad nacional de los bienes por encima de la propiedad específica particular, en clara actitud de rebasar incluso la misma ley que lo creó, pues ella más bien le daba al Estado un poder discrecional y de control e injerencia en el manejo de los bienes culturales coloniales de propiedad privada, pero jamás desarrolló el concepto de propiedad nacional de esto ${ }^{28}$. Ante tanta diferencia de opiniones, el ministro de Educación, en carta al de Relaciones Exteriores, manifestaba que aunque cumplía con trasladar el pedido del Consejo Nacional a la Iglesia era necesario llegar a un acuerdo entre las partes.

En medio de la polémica, y apoyando al Consejo Nacional, en la Cámara de Senadores se presenta un proyecto de ley donde específicamente son incluidos los bienes en posesión de la Iglesia en el trabajo de inventario del organismo estatal. Por oficio interno del 6 de setiembre de 1944 al arzobispo de Lima monseñor Farfán de los Godos, tanto el arzobispo del Cuzco como los obispos de Huánuco y Cajamarca, y el administrador apostólico de Madre de Dios, sostienen que como estrategia para enfrentar la crisis se debería:

1. Sostener "en principio" la doctrina del oficio del Episcopado dirigido al ministro de Culto el 18 de diciembre de 1943.

2. Contestar que, llegado el caso, el inventario de bienes tendrá que reglamentarse con el concordato que debe suscribirse y que el presidente ha dicho que debe hacerse.

3. Que sería conveniente que los señores obispos nombraran un delegado ante la Comisión Arzobispal de Monumentos y Obras de Arte Religioso, organismo eclesial creado para contrabalancear el poder del Consejo Nacional, y así reforzarlo y darle mayor prestigio ${ }^{29}$.

El 21 de setiembre, por carta al arzobispo de Lima, monseñor Mariano Holguín, arzobispo de Arequipa, manifiesta su acuerdo con todo lo actuado, apoya el esfuerzo de los otros obispos y anuncia que nombrará a un delegado ante la Comisión de Monumentos ${ }^{30}$. Sin embargo es el arzobispo de Trujillo, en carta del 7 de octubre a su colega de Lima, quien asume la posición más realista. Recuerda que en la Cámara de Senadores ya se ha aprobado el proyecto que dispone que el Consejo Nacional inventaríe los bienes eclesiásticos, y que pronto será sancionado en Diputados, por lo que cree que el "subterfugio 
del proyectado concordato", para detener el inventario, no va a ser tomado en cuenta por el gobierno. Por lo que opina que lo mejor sería una resistencia frontal "a ley tan inicua. La pretendida inventarización es el comienzo del despojo de los pocos bienes que le quedan a la Iglesia"31.

A la larga la Iglesia no logró su cometido de verse excluida del inventario del Consejo Nacional, pero tampoco este lo pudo culminar. Falta de recursos económicos, rechazo de los propietarios de bienes y poco interés del Estado en secundarlo llevaron a un trabajo más bien lento que se fue perdiendo con los meses y los años. La Iglesia, por otro lado, siempre buscó que se entendiera que ella podía regular sus bienes. En esos meses de 1944, la abadesa del monasterio del Prado (descalzas), informó el 3 de agosto a monseñor Farfán que había compradores de dos lienzos coloniales que ellas deseaban vender pues estaban necesitadas de recursos económicos. Al día siguiente el obispo auxiliar pidió informe al presidente de la Comisión Arquidiocesana de Monumentos y Objetos de Arte Religioso, José de la Riva-Agüero y Osma. El 6 la comisión, a través de su presidente, rechazó tal posibilidad pues "se debe negar sistemáticamente todo permiso para enajenar objetos artísticos" 32 .

Hay pues un creciente interés conservacionista por parte del Estado y de diversas personalidades públicas, paralelo a un cierto temor de la Iglesia por el destino de sus bienes, lo cual a su modo es igualmente una preocupación por su patrimonio material. El 3 de marzo de 1945 el nuncio apostólico Fernando Cento tramitó ante el Arzobispado de Lima el pedido del cardenal Marmaggi, prefecto de la Sagrada Congregación del Concilio, para que se le informara acerca de la administración de los bienes parroquiales en Lima. Le enviaron las normas aprobadas sobre administración de bienes del XIV Sínodo Arquidiocesano de $1935^{33}$.
Pero si bien la normatividad y la preocupación cotidiana fueron incrementándose, los descuidos y el progresivo coleccionismo de las elites limeñas socavaban al mismo tiempo este esfuerzo. En el Arzobispado del Cuzco había unas trescientas capillas rurales poseedoras de obras artísticas de inocultable valor. Los ecónomos y otros cuidadores de estas capillas, la mayor parte en pequeños pueblos o comunidades campesinas, recibían pequeñas parcelas para su sustento a cambio del cuidado de estos recintos. Este sistema de administración aquí y en otros lugares de las serranías se resquebrajó luego de 1950, debido a la toma de tierras y otros problemas sociales que afectaron a la agricultura, contribuyendo a que muchas obras artísticas empezaran a fluir hacia las manos de los coleccionistas privados.

Augusto Thorndike, ex ministro de Justicia de Manuel Prado, fue denunciado en 1958 por el agente fiscal suplente de Ayacucho, Luis García Blóndez, por haberse hecho "regalar" una tela con escena de la Sagrada Familia, inventariada por el Consejo Nacional de Conservación y Restauración. El acusado se defendió diciendo que la había traído a Lima para restaurarla. El fiscal y la diócesis no opinaron lo mismo ${ }^{34}$. A este caso podríamos agregar el de Berckemeyer Pazos, embajador del Perú en Washington durante los largos gobiernos de Manuel A. Odría (1948-1956) y segundo de Manuel Prado Ugarteche (19561962), y el caso de Celso Pastor de la Torre, embajador siguiente en Estados Unidos, en tiempos del presidente Fernando Belaunde Terry (19631968). Ambos se hicieron muy conocidos por tener colecciones privadas de arte colonial peruano en sus residencias americanas, que según ellos eran una manera de presentar el Perú al mundo.

Finalmente agreguemos el caso, ya al filo de los años de nuestro estudio, de la lenta conformación de la colección privada de Pedro de Osma, miembro de una vieja familia limeña. Este

\footnotetext{
31 AAL. CMN. XLVIII, 181. Trujillo 1944.

32 AAL. Descalzas, XVI. Siglo XX. Registros y Fianzas 1900-1950.

33 ML. CMN. XLVIII. 256. Lima 1945.

34 Caretas, VIII, 159 (1958) 14.
} 
coleccionismo -entendido como inversión, estatus social y también recuperación de la memoria histórica-y los coleccionistas internacionales, terminaron siendo los destinos últimos de multitud de piezas coloniales eclesiales que salían de oratorios, capillas, iglesias, conventos y monasterios, fruto de robos pero también de la desidia de guardianes laicos y del mismo clero.

\section{CUZCO, PATRIMONIO Y CONSERVACIÓN}

Este coleccionismo criollo solía repetirse entre las elites regionales, en Cuzco por ejemplo, donde era normal que las familias distinguidas de la ciudad tuvieran obras de arte en sus casas, en distintos ambientes, desde recibidores hasta las cocinas, prueba de su facilidad de recursos patrimoniales pero también de su despreocupación por estos. Al mudarse a Lima o el extranjero, fenómeno que se hizo común para esta vieja elite desde mediados del siglo $\mathrm{XX}$, terminaron vendiendo la mayor parte de sus colecciones a americanos o a limeños, insertos en el proceso de formación de colecciones privadas. Hubo también casos de transferencias de bienes a sirvientes o amigos. En el caso particular del Cuzco, el terremoto de 1950 es clave tanto para la aceleración de esta ola de transferencias de bienes y de formación moderna del coleccionismo, como para la agudización de las tendencias conservacionistas.

Tras el interés despertado por las adquisiciones de los viajeros extranjeros del siglo XIX, del surgimiento del indigenismo revalorizador de la cultura andina desde inicios del siglo XX y de la aparición del turismo desde los años veinte ${ }^{35}$ se habían formado auténticas redes públicas de comercialización de bienes no solo prehispánicos sino también coloniales ${ }^{36}$, que afectaban a los bienes artísticos en general, y específicamente a los eclesiásticos, no obstante que desde 1939 existía como sabemos un Consejo Nacional de Conservación y Restauración de Monumentos, con una visión conservacionista, y en el Cuzco el Instituto Americano de Arte, compartiendo tam. bién esta perspectiva. El testimonio de Julio G. Gutiérrez Loayza, presidente de dicho instituto en 1945, frente a unos lienzos que estaban abandonados en una iglesia rural, es significativo de lo que realmente sucedía: "se sabe de fuentes autorizadas que los organismos oficiales encargados de la custodia de las obras artísticas han hecho reiteradas gestiones ante la superioridad eclesiástica para asegurar, por lo menos, los valiosos lienzos, pero han tropezado con la tozudez inconcebible de quienes están obligados a resguardar los bienes que no solo pertenecen al culto sino que forman parte del patrimonio nacional".

Acusaba no solo a la jerarquía eclesiástica cuzqueña de desinterés por el cuidado de los bienes, poniéndose al lado del Consejo Nacional en la lucha ya revisada por "nacionalizar" los bienes patrimoniales de la Iglesia, sino también a los custodios campesinos, que a veces -decíaformaban parte de esas redes que satisfacían los requerimientos de los grandes coleccionistas nacionales y extranjeros. Recordaba en ese sentido cómo se habían perdido obras de arte del templo de Santa Catalina ${ }^{37}$. Constatación del expolio a la Iglesia, pero también argumentos para criticarla. Para 1948 la sección de Monumentos Históricos, Museos, Inventarios y Catalogación de la Corporación Nacional de Turismo, entidad estatal de fomento del turismo $y$ de administración de hoteles y hospedajes, ya realizaba igualmente una labor importante de catalogación de cuadros y otras obras de arte, aunque no circunscrita a material de propiedad eclesiástica.

35 En 1937 Uriel Garcia habia fundado el Instituto Americano de Ante, y en 1944, a instancias de Humberto Vidal Unda, vicepresidente de dicha institución, se creó un dia para el Cuzco, escogiéndose con innegables reminiscencias indigenistas el 24 de junio, dia del solsticio de invierno, en el cual los incas solian celebrar el Inti Raymi. Como refiere Tamayo Herrera: "Se escogió por una razón práctica, en junio no llueve y la fiesta del Corpus (la gran fiesta mestiza del Cuzco colonial) está próxima, y la ausencia de lluvias permite organizar un gran espectáculo al aire libre". Razones turísticas entonces. Roberto Ojeda y Luis Nieto compusieron la letra y música del Himno del Cuzco y en junio de 1944 Nieto compondría su poema "Canto al Cuzco y sus piedras sagradas". De esa época datan las investigaciones de John Rowe sobre el Cuzco inca, de Enrique Marco Dorta sobre arte y, en fin, de diversos intelectuales auspiciados por el Instituto Americano de Arte. lose Tamayo Herrera. Historia social del Cuzco republicano, p. 188

36 "En una venta de obras antiguas que se hizo en meses pasados al gobiemo en esta ciudad donde tuve la suerte de ser tasador... me reservé un hermoso catre tallado y do rado con la idea de que sea para usled si le agrada; el consejero de la Embajada de los Estados Unidos estuvo muy interesado...", le comentaba Teofilo Allain, desde el Cuzco, a José de la Riva-Aguero y Osma pero este, fiel a su postura anterior ya mencionada, rechaza en carta del $17-X-1942$ tal posibilidad de esta u otras ventas en general, manifestando que solo le interesaba que se le copiara un cuadro original de un antepasado suyo; y como se habia promulgado entonces una ley que prohibía la salida de obras de arte antiguo de las provincias termina diciendo: "No quiero que se nos acuse de quebrantar reglamento alguno". losé de la Riva-Agüero y Osma. Obras completas. Lima, Pontificia Universidad Católica del Perú, 1993, tomo XII, pp. 343-352.

37 Citado por Mariana Mould de Pease. Apuntes interculturales. Conservación y uso de los bienes culturales de la Iglesia católica del Perú. Lima, Pontificia Universidad Católica def Peru, 2002, pp. 128-129. 
El terremoto del Cuzco de 1950 agrietó las torres de la catedral, destruyó las de la iglesia de La Compañía, la torre barroca del Coricancha, la occidental de la iglesia de Belén, la izquierda de San Sebastián y su fachada. Y se derrumbó casi integro el templo de San Cristóbal. A ello se agregó que el Servicio de Caminos del Ministerio de Fomento y la prefectura dieron inicio posteriormente a una demolición cruel del Cuzco viejo, prehispánico y colonial. Carlos Jiménez era el director de Caminos y el coronel José Torre Tagle el prefecto, quienes buscando "tapados" en viejas casonas ordenaban destrucciones unilaterales, bajo el pretexto de estar dañados los edificios y la necesidad de modernizar el casco central. El informe George Kubler de la Unesco afirmó que el $20 \%$ de destrucción se debió a este efecto posterior, para ampliar calles, avenidas, etc., sin medir las consecuencias de no restaurar, de no conservar ${ }^{38}$. Buena parte de los templos y conventos dañados iba a ser afectada por este afán demoledor, de no ser porque desde Lima Luis E. Valcárcel protestó enérgicamente ante esta destrucción inmisericorde. A los diez días del terremoto del 21 de mayo se ordenó oficialmente preservar los monumentos de la ciudad imperial ${ }^{39}$.

A petición de Valcárcel, el arquitecto Óscar Ladrón de Guevara se encargó directamente de la defensa y restauración de los monumentos incas y coloniales cuzqueños. Entre 1951 y 1956 fueron reconstruidos el templo y convento de la Merced, San Francisco, La Compañía, Belén, San Sebastián, y avanzaron rápidamente los trabajos en Santo Domingo y el seminario de San Antonio de $\mathrm{Abad}^{40}$. Desde 1950 hasta 1966 Ladrón de Guevara se desempeñó como jefe del Departamento de Reconstrucción de la Junta de Reconstrucción y Fomento Industrial del Cuzco, posteriormente Ilamada Corporación de Desarrolio, entidad autónoma creada por el Estado para canalizar los recursos tendientes a la reconstrucción de la ciudad y trazar e implementar un plan de desarrollo regional. El mencionado arquitecto, formado en Chile, reconstruyó varios monumentos, incorporando modernos materiales y técnicas, pero respetando las formas y estilos originales. Las obras en la catedral -iniciadas en 1951- recibieron subvenciones directas del gobierno de España y fueron realizadas por el arquitecto español Andrés León Boyer, reforzando las estructuras, aclarando ambientes y embelleciendo detalles. El 27 de abril de 1953 fueron inauguradas dichas obras.

Posteriormente la Junta de Reconstrucción y Fomento siguió con sus labores de reconstrucción y restauración hasta 1971, entregando sucesivamente obras en el Palacio Arzobispal, San Pedro, Santa Clara, Santa Teresa, La Recoleta, Santa Ana, Triunfo y Jesús María ${ }^{41}$. En ellas participaron activamente los ingenieros Vicente González Minauro, Guillermo Durand Teves, Eulogio Cabada, Lionel Villafuerte, Oswaldo Heredia, entre otros. Y maestros artesanos como los hermanos Bellota que labraron las piedras en San Sebastián y Santo Domingo, o el maestro cantero Tomás Dinos, o el tallador Celso Romero que trabajó el artesonado del Palacio Arzobispal. Igualmente Humberto Mansilla, que restauró las bóvedas de Santa Teresa y la capilla de Lourdes, o Julio Peña Ramos, que hizo una restauración del arco toral de la iglesia de la Compañía. La pintura colonial había merecido contemporánea atención de Felipe Cossío del Pomar en 1922 con su Pintura colonial, Escuela Cuzqueña, y otros trabajos. Posteriormente, la Junta y la Corporación de Desarrollo hicieron posible que Teófilo Benavente y Alejandro Martínez efectuaran una catalogación de cuadros y objetos de arte coloniales en la ciudad, y que con los años surgiera un equipo de restauradores plásticos, avizorando los tiempos por venir.

\section{EL PATRIMONIO SE MUESTRA AL MUNDO: CIRCUITOS TURÍSTICOS Y MUSEOS}

El terremoto de 1950 es vital para afincar el interés por conservar y restaurar en la ciudad. Pero además, ya dentro de la lógica de un turismo

38 George Kubler. Cuzco, reconstrucción de la ciudad y restauración de sus monumentos. Paris, 1953.

39 José Tamayo Herrera. Historia social del Cuzco republicano, pp. 177.191.

40 Junta de Reconstrucción y Fomento (Cuzco). Memoria de la Junta de Recanstrucción y Fomento del Cuzco. Cuzco, 1956.

41 Corporación de Reconstrucción y Fomento (Cuzco). Aemoria de la Corporación de Reconstrucción y fomento. Cuzco, 1967. 
en aumento, donde los visitantes extranjeros no se cuentan por centenas sino por miles anualmente, el terremoto es gravitante para despertar la conciencia entre los eclesiásticos por el mercado turístico. En 1954 llegaron 6,903 turistas, en 1964 fueron 38,939 y en 1975 la cifra alcanzaba los 176,626 visitantes. La explosión convierte a la ciudad-museo en una urbe dinámica, ágil. Hoteles, restaurantes, agencias de turismo $y$ diversos servicios se multiplican en esos años. La ciudad, fragmentariamente, encuentra una salida a la creciente decadencia de la economía agraria tradicional.

La Iglesia cuzqueña, como posteriormente la puneña, es testigo de estos cambios acelerados. Los turistas visitan masivamente la catedral, la iglesia de la Compañía y los templos de conventos y monasterios. Desde el nacimiento de los city-tours dichos edificios están plenamente incorporados a los circuitos habituales. El Cuzco como ciudad es incaico pero colonial, y allí el peso de lo religioso es esencial. Por efecto de esta vorágine demostrativa el Arzobispado de la ciudad consideró conveniente montar un museo diocesano. El Museo del Arzobispado, a partir de la donación de José Orihuela Yábar y de las obras pictóricas de la diócesis, nació con una idea muy clara de mostrar al mundo la riqueza cultural de la Iglesia, complementando sin duda la muestra prehispánica del Museo de la Universidad y del Museo de la Casa Garcilaso. No fue el único esfuerzo: monasterios como el de Santa Catalina terminarían también montando sus propios museos, organizado en este caso por el boliviano José de Mesa, quien en 1962 junto a Teresa Gisbert publicaría su Historia de la pintura cuzqueña.

La exhibición de patrimonio y el aprovechamiento de la vorágine turística -que posteriormente se extenderían a Puno y Arequipa- no se dieron solo en Cuzco. En verdad unos años antes del terremoto ya en Lima se experimentaba esa inclinación. Desde 1940 existía en la capital un interés racional por el turismo, que posteriormente se masificaría con los traslados aéreos. La Iglesia también le presta atención a esta tendencia, particularmente una congregación religiosa: los franciscanos. La provincia franciscana de los Doce Apóstoles o provincia peruana tiene entre sus bienes más preciados en la Lima cuadrada la iglesia y convento de San Francisco, conjunto arquitectónico y religioso que a pesar de haberse reducido en extensión con el tiempo, conserva en buen estado su iglesia principal, capillas anexas y convento. Previendo un futuro donde el mantenimiento de un edificio de esta naturaleza sería oneroso y en procura de medios para su cuidado, surge en esos años el afán por mostrarlo al turismo extranjero $y$ nacional.

Como podemos apreciar en la guía de Benjarnín Gento Sanz OFM, de setiembre de 1945, publicada en formato de cuadernillo, con 80 páginas y fotos en blanco y negro, se trata tanto de presentar a través de la visita a este monumento la historia de los franciscanos en Lima y el Perú -y su inserción feliz en la historia de la ciudad-como de demostrar el aporte de la Iglesia a la historia lo$\mathrm{cal}^{42}$. Recorriendo el claustro principal, la biblioteca, las pinturas insertas en las paredes, el comedor, las distintas salas, el templo, el coro, etc., $y$ las catacumbas -posteriormente agregadas al recorrido- uno puede percatarse de lo que era un convento en la ciudad virreinal, del significado de lo religioso en la mente de las personas, plasmado en pinturas $y$ en las obras de alarifes y canteros.

El recorrido inicial por el convento pronto se convirtió en punto obligado de los turistas extranjeros de paso por Lima y también en requisito para los nacionales deseosos de conocer la Lima virreinal. La doble dimensión, planteada por Gento, Tibesar y los que plasmaron esta idea de convento-museo, permitió en forma rápida incorporar San Francisco al circuito turístico limeño. La ventaja temporal lograda, respecto a otros monumentos religiosos que se insertaron después, ha permitido que sea difícil sustituirlo como el monumento colonial más importante de la ciudad.

Así pues conservación y turismo se empezaron a dar la mano y, lo que es más importante, la Iglesia 
adquirió -en Lima y Cuzco- una definitiva conciencia de los bienes patrimoniales que tenía. Con los años otros monumentos religiosos se incorporaron a los circuitos turísticos de estas ciudades y por cierto el concepto de patrimonio mostraría claramente su doble índice material y espiritual. La historia nos remite al interés creciente por la procesión del Señor de los Milagros, la visita obligada a Santo Domingo para contemplar la tumba de San Martín de Porres, o la asistencia a la basílica de Santa Rosa. Y en el Cuzco son imprescindibles la visita a Coricancha y su arquitectura mestiza o la concurrencia a la procesión del Señor de los Temblores o el Corpus.
Procesos inmediatos posteriores, donde la Iglesia perdió sus temores frente al Estado y a los organismos estatales culturales, abandonando en gran parte sus objeciones a efectuar inventarios y, sobre todo, tomó conciencia de la necesidad de mostrar sus bienes artísticos tanto a la comunidad local como al turista extranjero, prueba fidedigna de su patrimonio cultural y también una certeza de que hechos públicos sus bienes había menos posibilidad de ser expoliados. La gestión turística de los edificios eclesiásticos de Lima y Cuzco fue índice del nuevo rumbo de los acontecimientos. 